\title{
Pathophysiology of Rhinitis
}

\section{Lactoferrin and Lysozyme in Nasal Secretions}

Gordon D. Raphael, Elizabeth V. Jeney, James N. Baraniuk, Irene Kim, Scott D. Meredith, and Michael A. Kaliner Allergic Diseases Section, Laboratory of Clinical Investigation, National Institute of Allergy and Infectious Diseases, National Institutes of Health, Bethesda, Maryland 20892

\begin{abstract}
The antimicrobial proteins lactoferrin (Lf) and lysozyme (Ly) are invariably found in nasal secretions. To investigate the cellular sources and the secretory control of these nasal proteins in vivo, 34 adult subjects underwent nasal provocation tests with methacholine (MC), histamine (H), and gustatory stimuli. Nasal lavages were collected and analyzed for total protein (TP), albumin (Alb), Lf, and Ly. MC (25 mg), H (1 $\mathrm{mg}$ ), and gustatory stimuli (spicy foods) all increased the concentrations of TP, Alb, Lf, and Ly. However, when each protein was assessed as a percentage of TP (i.e., Alb\% = Alb/TP; $\mathrm{Lf} \%=\mathrm{Lf} / \mathrm{TP} ; \mathrm{Ly} \%=\mathrm{Ly} / \mathrm{TP}), \mathrm{MC}$ and gustatory stimuli, which both induce glandular secretion, selectively augmented Lf\% and Ly\% without changing Alb\%, while $H$, which primarily increases vascular permeability, increased Alb\% without significantly affecting $\mathrm{Lf} \%$ or Ly\%. Gel electrophoresis and immunoblotting analysis of nasal secretions demonstrated both Lf and Ly in cholinergically induced secretions. Furthermore, histochemical analyses of nasal turbinate tissue revealed Lf and Ly colocalization within the serous cells of submucosal glands, providing evidence that both proteins are strictly glandular products within the nasal mucosa. Therefore, both $\mathrm{Lf}$ and Ly are produced and secreted from the glands, and their secretion may be pharmacologically regulated in attempts to improve host defenses.
\end{abstract}

\section{Introduction}

The sources of human nasal secretions have been previously analyzed by measuring the secretion of albumin (Alb), ${ }^{1}$ secretory $\operatorname{IgA}(\mathrm{s} \operatorname{Ig} \mathrm{A})$, nonsecretory $\operatorname{IgA}$, and $\operatorname{IgG}$ into induced nasal secretions $(1,2){ }^{2}$ It was demonstrated that $\operatorname{sIgA}$ is a protein produced locally in the nasal mucosa, processed exclusively by the submucosal glands (1). The secretion of $\operatorname{sIgA}$ into nasal secretions is regulated by processes that govern glandular secretion (e.g., the cholinergic nervous system), and therefore sIgA can be used as a marker of glandular secretion. In con-

Address reprint requests to Dr. Gordon Raphael, National Institutes of Health, Bldg. 10, 11C207, Bethesda, MD 20892.

Received for publication 23 November 1988 and in revised form 5 June 1989.

1. Abbreviations used in this paper: Alb, albumin; Alb\%, albumin percent; H, histamine; Lf, lactoferrin; Lf\%, lactoferrin percent; Ly, lysozyme; Ly\%, lysozyme percent; MC, methacholine; sIgA, secretory IgA; TP, total protein.

2. Meredith, S. D., G. D. Raphael, J. N. Baraniuk, S. M. Banks, and M. A. Kaliner. 1990. The pathophysiology of rhinitis III: the control of IgG secretion. J. Allergy Clin. Immunol. In press.

The Journal of Clinical Investigation, Inc.

Volume 84, November 1989, 1528-1535 trast, the serum proteins Alb, non-sIgA, and IgG enter nasal secretions through at least two mechanisms: by increased extravasation from blood vessels into interstitial fluid and transport across the respiratory epithelium into the nasal cavity; or by passage across specialized capillary fenestrae, uptake by the submucosal glands, and transport into the glandular lumen, thus entering the nose as a component of glandular secretions (1). ${ }^{2}$

The sources of the constituent proteins in nasal secretions have been determined by analyzing nasal provocation with methacholine (MC) (1) and histamine $(\mathrm{H})(2)$, or by stimulating glandular hypersecretion with spicy food challenges, producing a syndrome referred to as gustatory rhinitis (3). While we now have a rudimentary understanding of the sources and controls of some of the proteins found in nasal secretions, the origin and function of most of the other proteins found in respiratory secretions (Table I) have not been fully explored. In particular, two antimicrobial proteins, lactoferrin (Lf) and lysozyme (Ly), are described in nasal secretions, yet the origin and cellular sources of these two proteins have not been adequately determined. The purpose of this report is to demonstrate that both of these proteins are of glandular origin, and that their secretion into airway secretions can be controlled pharmacologically.

\section{Methods}

\section{Subjects}

34 adult subjects ( 11 male, 23 female) between the ages of 19 and $52 \mathrm{yr}$ were studied after informed consent was obtained. Subjects were not studied within $3 \mathrm{wk}$ after recovering from an upper respiratory tract infection, and no subject experienced nasal symptoms at the time of study. No medications were taken within $48 \mathrm{~h}$ of nasal challenge. Atopic subjects were defined as having seasonal symptoms of rhinitis and were skin test positive to relevant allergens as determined by prick tests with a battery of inhaled aeroallergens. Atopic subjects $(n=15)$ were studied outside of their allergy season during asymptomatic periods. Nonatopic subjects $(n=19)$ had no allergy symptoms and were skin test negative.

\section{Challenge methods}

Nasal challenges were performed as previously described (1). Nasal lavage fluid was collected through $8 \mathrm{~F}$ rubber catheters. After the nasal cavity was washed with four 4-ml saline prewashes, the challenge protocols formally began.

All nasal challenge solutions were delivered to only one side of the nasal cavity from a hand-held nebulizer bottle. Challenge solutions $(0.3 \mathrm{ml}$ each) were diluted in normal saline. Each challenge period (10 $\mathrm{min}$ ) was followed by a 4-ml saline lavage.

In the first protocol subjects were challenged sequentially with saline and then $25 \mathrm{mg}$ of MC. In the second challenge protocol saline challenge was followed by a challenge with $1 \mathrm{mg}$ of $\mathrm{H}$.

The third protocol was a different type of challenge protocol and consisted of oral food challenges combined with nasal lavages. Each 
Table I. Protein Constituents of Nasal Secretions

$\begin{array}{ll}\text { Alb } & \text { Alpha-galactosidase } \\ \text { Ly } & \text { Succinic dehydrogenase } \\ \text { Lf } & \text { IgA, IgE, IgG, SC } \\ \text { Kallikrein } & \text { Glutamate dehydrogenase } \\ \text { Antiproteases } & \text { Leucineaminopeptidase } \\ \text { Beta-glucuronidase } & \end{array}$

subject slowly consumed a food item, and then the nasal cavity was lavaged with $4 \mathrm{ml}$ of saline after $10 \mathrm{~min}$. Control foods were defined as those foods that historically were not associated with rhinorrhea, and consisted of wheat crackers, pretzels, sweet peppers, or gefilte fish. Positive foods were foods that historically always produced rhinorrhea in this study population, and included hot chili peppers, horseradish, and hot and sour soup.

\section{Assays}

Total protein. Protein in nasal lavage samples was measured by the Lowry method (4) using BSA as the standard.

Albumin. Human serum Alb was measured by a competitive ELISA as previously reported (1). The assay range was between 1 and $100 \mu \mathrm{g} / \mathrm{ml}$.

Ly. Ly was measured by a turbidimetric assay based on the enzymatic hydrolysis of bacterial cell walls (5). $50 \mu$ l of Ly standard (Sigma Chemical Co., St. Louis, MO) or sample was added to a 1-ml suspension of Micrococcus lysodeikticus $(0.25 \mathrm{mg} / \mathrm{ml}$ in $0.1 \mathrm{M} \mathrm{PBS}, \mathrm{pH} 7.0)$, and the decrease in absorbance per minute at $450 \mathrm{~nm}$ was recorded on a spectrophotometer (Hewlett Packard Co., Palo Alto, CA). The range of the assay was between 1 and $100 \mu \mathrm{g} / \mathrm{ml}$.

$L f$. Lf was measured by a modified noncompetitive ELISA (6). 100 $\mu l$ of rabbit anti-human Lf (Dako Corp., Santa Barbara, CA), diluted $1: 1,000$ in $0.1 \mathrm{M}$ carbonate buffer, $\mathrm{pH} 9.6$ (coating buffer), was added to a polyvinylchloride microtiter plate and incubated at $37^{\circ} \mathrm{C}$ for 90 min. The wells were then blocked with $1 \%$ goat serum (Gibco Laboratories, Grand Island, NY) diluted in a buffer (PT) consisting of PBS, pH 7.4, and 0.05\% Tween 80 (Fisher Scientific Co., Pittsburgh, PA). Standards of Lf (Sigma Chemical Co.) or sample (100 $\mu$ l) were then incubated at $37^{\circ} \mathrm{C}$ for $90 \mathrm{~min}$. The plates were washed and rabbit anti-human Lf-horseradish peroxidase conjugate (Cappel Laboratories, Cochranville, PA), diluted 1:1,000 in PT, was added to each well and again incubated at $37^{\circ} \mathrm{C}$ for $90 \mathrm{~min}$. The reaction was developed with an $o$-phenylenediamine dihydrochloride substrate (Sigma Chemical Co.) and read at $490 \mathrm{~nm}$. The assay range was between 1 and 200 $\mathrm{ng} / \mathrm{ml}$.

Alb percent (Alb\%), Ly percent ( $L y \%)$, and $L f$ percent (Lf\%). The $\mathrm{Alb} \%$, $\mathrm{Ly} \%$, and $\mathrm{Lf} \%$ were calculated by dividing the respective proteins by the total protein (TP) and multiplying by $100 \%$.

\section{Protein electrophoresis and immunoblots}

Protein electrophoresis. PhastGel 10-15\% gradient polyacrylamide gels, SDS buffer strips, sample applicators, PhastSystem separation and control unit, development unit, and Coomassie blue dye were obtained from Pharmacia Fine Chemicals (Piscataway, NJ). Ly ( $1 \mathrm{mg} / \mathrm{ml})$, Lf $(100 \mu \mathrm{g} / \mathrm{ml})$, and nasal secretion samples were reduced and denatured with beta-mercaptoethanol and SDS (7). Each sample $(1 \mu \mathrm{l})$ was applied to $10-15 \%$ polyacrylamide gels, which were then electrophoresed and stained for protein with Coomassie blue as described (8).

Western blot and immunodetection of proteins. Proteins were transferred from the gels to nitrocellulose by unidirectional diffusion blotting as described (9). In brief, nitrocellulose wetted with distilled water was superimposed on the gel and the PhastSystem separation and control unit was heated to $70^{\circ} \mathrm{C}$ for $45 \mathrm{~min}$. The method of immunodetection of proteins has been previously described (9). Nitrocellulose blots were incubated in $3 \%$ BSA in a Tris buffer $(0.9 \%$
$\mathrm{NaCl}, 10 \mathrm{mM}$ Tris- $\mathrm{HCl}, \mathrm{pH} 7.4$ ) for $1 \mathrm{~h}$ at $40^{\circ} \mathrm{C}$. After this blocking step blots were rinsed in two changes of Tris buffer. The blots were then incubated in the first antibody (rabbit anti-human Ly or rabbit antihuman Lf [Dako Corp.]) diluted 1:2,000 in Tris buffer containing 3\% BSA and $10 \%$ goat serum for $2 \mathrm{~h}$ at room temperature. After washing with five changes of Tris buffer over $30 \mathrm{~min}$ the blots were incubated with the second antibody (alkaline phosphatase-conjugated goat antirabbit IgG, diluted $1: 2,000$ in Tris buffer containing 3\% BSA and $10 \%$ goat serum) for $2 \mathrm{~h}$ at room temperature. After washing with five additional changes of Tris buffer the blots were developed with BCIP/ NBT alkaline phosphatase substrate (Kirkegaard \& Perry Laboratories, Inc., Gaithersburg, MD) for $50 \mathrm{~min}$ at room temperature. The color reaction was terminated by washing the blots with large volumes of distilled water.

\section{Indirect immunohistochemistry}

Human inferior nasal turbinates $(n=6)$ were obtained from patients who underwent turbinectomies for nasal obstruction syndromes. The tissue was fixed in $4 \%$ paraformaldehyde in $\mathrm{pH} 7.4 \mathrm{PBS}$ at $4^{\circ} \mathrm{C}$ for $18 \mathrm{~h}$. Paraffin-embedded sections were cleared in xylene and graded alcohols, and washed in water, PBS, and then $1 \%$ nonimmune serum in PBS. Tissue sections were incubated in rabbit antisera to human Alb, $\mathrm{Ly}$, or $\mathrm{Lf}$ for $20 \mathrm{~h}$ at $4^{\circ} \mathrm{C}$ in a humidified chamber. After washing with PBS one of two second antibody systems was used. Either colloidal gold-labeled goat anti-rabbit IgG (Auroprobe; Janssen Life Sciences Products, Piscataway, NJ) was used with silver enhancement (IntenSE, Janssen Life Sciences Products), or biotinylated goat anti-rabbit IgG was used with avidin-horseradish peroxidase (Vectastain; Vector Laboratories, Inc., Burlingame, CA) and with 3,3'-diaminobenzidine as the chromogen. Some sections were counterstained with Alcian blue, which stains mucous cells.

\section{Statistics}

Data are expressed as the mean \pm SEM. The two-sample Wilcoxon test (a nonparametric version of the $t$ test) was used for statistical comparisons of control samples with challenge samples.

\section{Results}

Protein, Alb, and Alb\%. 12 subjects were studied in the MC challenge protocol. The dose of MC used (25 mg) was previously established as effective in inducing glandular secretion (1). As previously reported, saline provocation did not cause any nasal symptoms, while MC reliably stimulated rhinorrhea, a short-lived nasal congestion, and/or a mild facial flushing in all subjects.

Total protein, Alb, and Alb\% data are shown in Fig. 1. Compared with saline control challenge, MC significantly in-

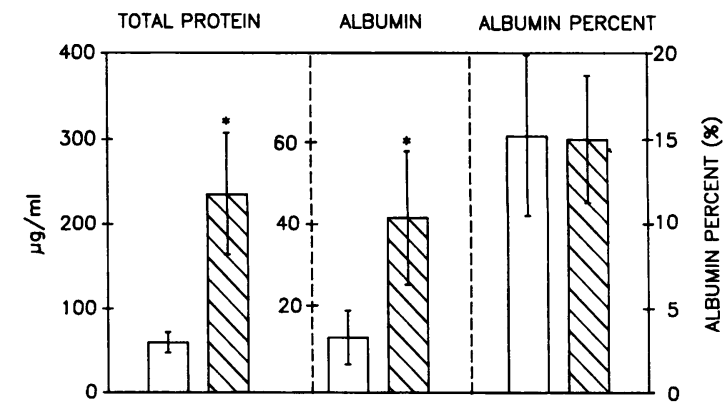

Figure 1. TP, Alb, and Alb\% in nasal lavages after MC challenge ( $n$ $=12$ ). Nasal lavages were collected $10 \mathrm{~min}$ after challenge with saline (control; open bars) and then with $25 \mathrm{mg}$ of MC (hatched bars). Bars represent the mean \pm SEM. ${ }^{*} P<0.005$. 


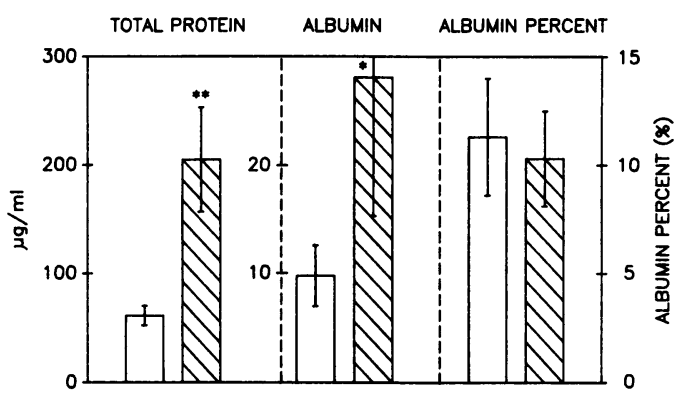

Figure 2. TP, Alb, and Alb\% in nasal lavages after food challenge with a control food (open bars) followed by a positive food (hatched bars $)(n=15)$. Bars represent the mean \pm SEM. ${ }^{*} P<0.005 ;{ }^{* *} P$ $<0.0005$.

creased the TP and Alb secretion. In contrast, Alb\% was virtually unchanged by $\mathrm{MC}$ challenge, reflecting a proportional increase in both Alb and TP after cholinergic stimulation.

Food challenges were performed in 15 subjects as a method of inducing endogenous cholinergically induced nasal secretion. It has previously been shown that positive (spicy) foods induce nasal secretions through a reflex-mediated cholinergic mechanism (3). Control (bland) foods failed to stimulate nasal secretions in any subject. Positive foods, on the other hand, induced watery nasal secretions (gustatory rhinitis) in all 15 subjects. The TP, Alb, and Alb\% data from this study are shown in Fig. 2. As with the MC challenge study, both TP and Alb increased significantly, while the Alb\% was essentially unchanged by positive food challenge.

$\mathrm{H}$ challenge $(n=26)$ produced more dramatic nasal symptoms including bouts of sneezing, moderate to severe nasal congestion, profuse watery and mucoid nasal discharge, and occasional facial flushing. In comparison to the previous cholinergic challenges, the magnitude of TP and Alb secretion was more profound (Fig. 3). In addition to the significant increases in TP and Alb, the Alb\% also increased significantly. This increase in Alb\% has previously been attributed to an increase in vascular permeability (2).

$L f$. Lf was measured and $\mathrm{Lf} \%$ calculated in these same nasal lavages. As shown in Fig. 4, both MC and positive foods significantly increased Lf protein secretion above control levels. In addition, the Lf\% increased significantly after MC challenge, and increased (although not significantly) after food challenge, suggesting a glandular origin for $\mathrm{Lf}$ secretion. $\mathbf{H}$

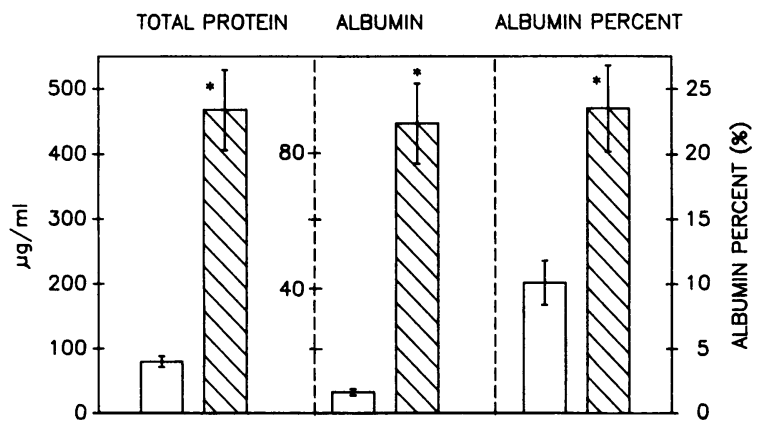

Figure 3. TP, Alb, and Alb\% in nasal lavages after $\mathrm{H}$ challenge ( $n$ = 33). Open bars, control; hatched bars, $\mathrm{H}(1 \mathrm{mg})$. Bars represent the mean \pm SEM. ${ }^{*} P<0.0001$

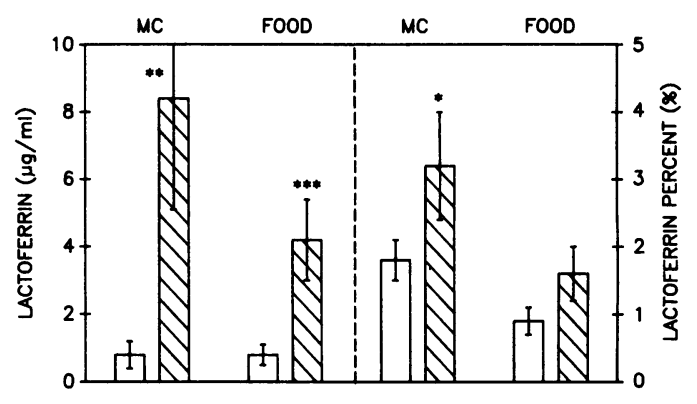

Figure 4. Lf secretion and Lf\% in nasal lavages after MC challenge and food challenge. Control challenge (saline or control food; open bars) was followed by positive challenge (MC or positive food; hatched bars). Bars represent the mean \pm SEM. ${ }^{*} P<0.01 ;{ }^{* *} P$ $<0.005 ;{ }^{* * *} P<0.0005$.

produced a comparable increase in Lf secretion (Fig. 5). However, in contrast to cholinergic stimuli the Lf\% actually decreased (although not significantly) after $\mathbf{H}$ challenge. Since $\mathbf{H}$ has been shown to stimulate predominantly increased vascular permeability at this 1-mg dose (2), the lack of increase in Lf\% after $\mathrm{H}$ challenge suggests that $\mathrm{Lf}$ is being diluted by serum proteins, consistent with the suggestion that $\mathrm{Lf}$ is a glandular secretion.

$L y$. In a similar manner, Ly was measured in nasal lavages from the above protocols. Ly secretion paralleled $\mathrm{Lf}$ secretion (Table II), increasing dramatically in concentration after cholinergic stimulation as well as after $\mathrm{H}$ stimulation (Figs. 6 and 7). Ly\% was found to represent $5-15 \%$ of baseline nasal secretory proteins and to increase significantly after cholinergic stimulation to $15-25 \%$ of TP. By contrast, $\mathrm{H}$ stimulation did not change the Ly\%.

Because of the surprisingly high percentage of Ly in both baseline secretions and stimulated secretions, it was necessary to confirm that the measured Ly activity was indeed genuine. Several confirmatory tests were therefore performed.

In the first test, known concentrations of Ly were added to a pooled sample of nasal secretions. As shown in Fig. 8, Ly standards added to pooled nasal secretions resulted in parallel measurements as compared with standards added to buffer only. Therefore nasal secretions did not affect the assay system and did not artificially elevate the measured values of Ly. In another test, the addition of a rabbit anti-human Ly (1:8 dilution) specifically reduced measurable Ly activity in nasal secretions by $\sim 77 \%$.

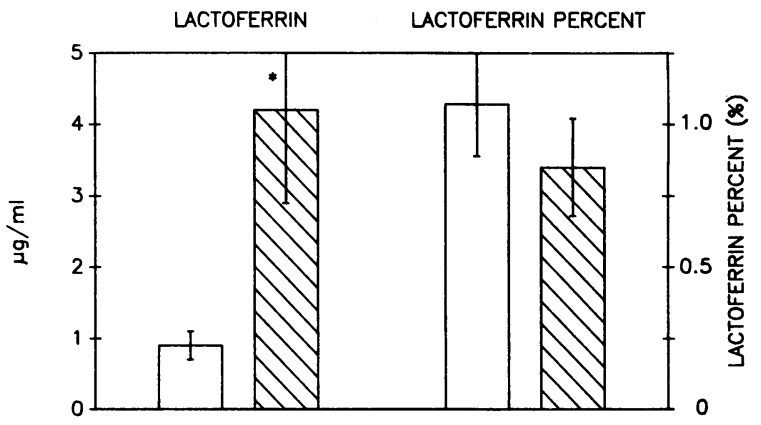

Figure 5. Lf secretion and $\mathrm{Lf} \%$ in nasal lavages after $\mathrm{H}$ challenge. Open bars, control; hatched bars, $\mathrm{H}(1 \mathrm{mg})$. Bars represent the mean \pm SEM. ${ }^{*} P<0.0005$. 
Table II. Spearman Rank Correlation Coefficients Comparing $L f$ and $L y$

\begin{tabular}{lccc}
\hline & $\begin{array}{c}\text { Saline vs. MC } \\
(25 \mathrm{mg})\end{array}$ & $\begin{array}{c}\text { Control food challenge } \\
\text { vs. positive food challenge }\end{array}$ & $\begin{array}{c}\text { Saline vs. H } \\
(1 \mathrm{mg})\end{array}$ \\
\hline & & & \\
Lf vs. Ly & $0.68^{*}$ & $0.76^{\ddagger}$ & $0.55^{\S}$ \\
Lf\% vs. Ly\% & 0.36 & 0.35 & 0.36 \\
\hline
\end{tabular}

${ }^{*} P<0.03 ;{ }^{\ddagger} P=0.002 ;{ }^{\S} P=0.004$.

To exclude the possibility that tears, which contain high concentrations of $\mathrm{Ly}(10,11)$, might contaminate the nasal secretions and account for the increased levels seen after challenge the following study was performed. Three additional subjects with ocular disease (uveitis) were given unilateral topical treatments with anticholinergic medications (Cyclogel or methscopalomine) and were then examined for nasal secretory responses to topical MC. All subjects were studied within 30 min of receiving topical anticholinergic treatment. Both sides of the nose were challenged with saline followed by $25 \mathrm{mg}$ of MC, and nasal lavages were collected 10 min after each challenge. Table III demonstrates that no significant differences were observed between TP, Lf, or Ly secretion from either side of the nose, indicating that the anticholinergic treatment, which prevents unilateral lacrimation, had no effect on the increases in nasal secretion Ly seen after MC stimulation. Since anticholinergic eye drops inhibit the active secretion of Lf or Ly from the lacrimal gland, it was concluded that the Lf and Ly in nasal lavages is derived from increased nasal glandular secretion and not from tear contamination.

Gel electrophoresis and Western blots. Gel electrophoresis was performed on both baseline and stimulated nasal secretions to identify the proteins in nasal secretions. In addition to the nasal lavage samples, standards of Alb, IgG, Lf, Ly, and IgA were run simultaneously on the same gels in an attempt to identify specific protein bands. As shown in Fig. 9, Coomassie blue-stained gels revealed several faint protein bands in baseline nasal secretions (lane 5). After MC challenge (lane 4) some of the bands became accentuated, and their locations corresponded with several of the standards (Alb, Lf, Ly, and Ig heavy chain).

Western blotting was then used to immunologically identify the presence of Lf and Ly in MC-stimulated nasal secretions. For each protein two gels were run in parallel, and while one gel was stained with Coomassie blue, the other gel was used to prepare Western blots. Both Lf and Ly immunoreactivity were identified on Western blots (Figs. 10 and 11), and their locations on the blots corresponded with their respective

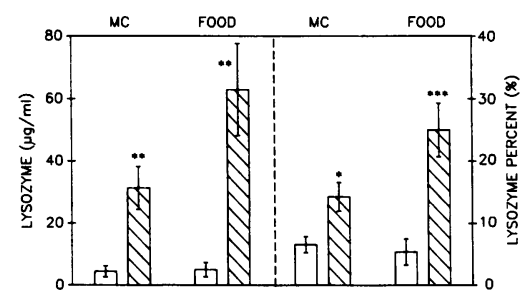

Figure 6. Ly secretion and $\mathrm{Ly} \%$ in nasal lavages after challenge with MC or food. Open bars, control challenge; hatched bars, positive challenge. Bars represent the mean \pm SEM. ${ }^{*} P<0.01 ;{ }^{* *} P<0.005$ ${ }^{*} P<0.001$.

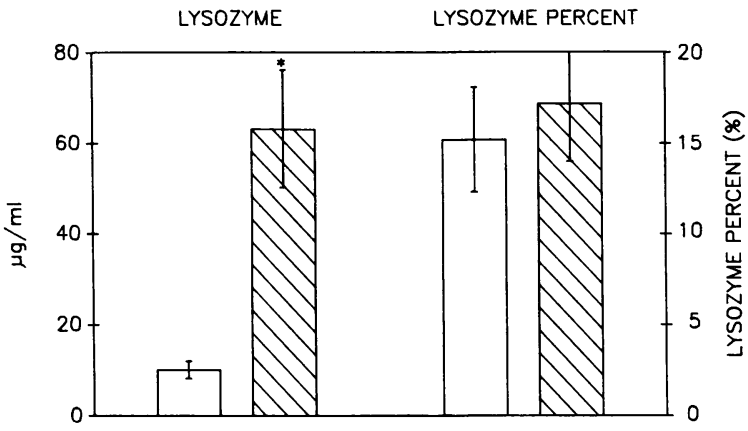

Figure 7. Ly secretion and Ly\% in nasal lavages after challenge with H. Open bars, control; hatched bars, $\mathrm{H}(1 \mathrm{mg})$. Bars represent the mean \pm SEM. ${ }^{*} P<0.0001$.

protein bands on the original gels. Thus, the presence of Lf and Ly in induced nasal secretions was confirmed by their pattern of movement during electrophoresis as well as by immunologic means.

Immunohistochemistry. Nasal turbinate tissue was stained immunohistochemically for Lf and Ly as described. As shown in Figs. 12 and 13, both proteins were found in all of the serous cells of the submucosal glands. On serial sections both $\mathrm{Lf}$ and Ly immunoreactivity were seen in the same cells, confirming the coexistence of both proteins within the same serous cells. Goblet cells of the respiratory epithelium and mucous cells of the submucosal glands, both of which stain positively with Alcian blue, and other respiratory epithelial cells that do not stain with Alcian blue, were devoid of Lf and Ly immunoreactivity. Careful examination of multiple nasal mucosal specimens confirmed the presence of two mutually exclusive subsets of submucosal gland cells: Alcian blue-negative, Lf/Ly immunoreactive-positive serous cells; and Alcian blue-positive, Lf/Ly immunoreactive-negative mucous cells.

\section{Discussion}

Nasal secretions contain proteins derived from several discrete sources including the vascular system, the submucosal glands, and cells within the nasal mucosa. This report demonstrates that Lf and Ly, two antimicrobial proteins previously described in nasal secretions, are produced and stored in the nasal submucosal glands, specifically within serous cells, and are secreted under the influence of the parasympathetic nervous system.

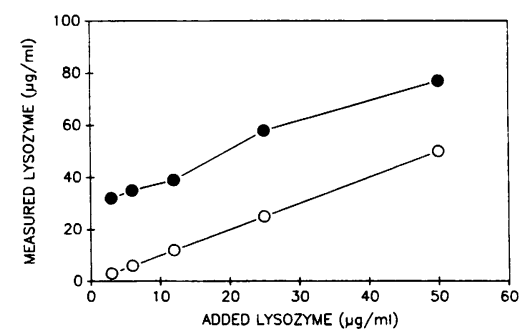

Figure 8. Measurement of Ly in pooled nasal secretions. Ly standards $(3,6,12,25$, and 50 $\mu \mathrm{g} / \mathrm{ml})$ added to pooled nasal secretions $(\bullet)$ or PBS (O) produced curves that were displaced in parallel. This suggests that nasal secretions neither augment nor decrease the measurement of Ly. 
Table III. Effect of Ocular Anticholinergic Treatment on MC-Induced Nasal LF and Ly Secretion

\begin{tabular}{lccccc}
\hline & \multicolumn{2}{c}{ Untreated side } & & \multicolumn{2}{c}{ Treated side } \\
\cline { 2 - 3 } \cline { 5 - 6 } & Saline & MC $(25 \mathrm{mg})$ & & Saline & MC (25 mg) \\
\hline $\operatorname{TP}(\mu g / \mathrm{ml})$ & $38.3 \pm 5.9$ & $160.8 \pm 39.0$ & & $55.0 \pm 10.3$ & $110.0 \pm 28.3$ \\
$\mathrm{LF}(\mu \mathrm{g} / \mathrm{ml})$ & $1.0 \pm 0.7$ & $4.4 \pm 1.3$ & & $0.9 \pm 0.2$ & $5.4 \pm 3.0$ \\
$\mathrm{Ly}(\mu \mathrm{g} / \mathrm{ml})$ & $7.3 \pm 0.5$ & $29.2 \pm 10.6$ & & $11.8 \pm 2.0$ & $33.3 \pm 11.4$
\end{tabular}

Lf is a 78,000 mol wt protein that exhibits both bacteriostatic and bactericidal properties $(12,13)$. It irreversibly binds two atoms of iron, and presumably this is the mechanism by which it exerts much of its antimicrobial properties. In addition, Lf also blocks the formation of complement factor $\mathrm{C} 3$ convertase, regulates granulocyte production, and regulates the production of macrophage colony-stimulating factor (13). The significance of these latter properties of Lf remains unclear.

Lf is commonly found in the external secretions of both nonhumans and humans. It was first described in bovine milk in 1966 (14). In the human Lf has been found in tears, nasal secretions, bronchial mucus, urine, seminal fluid, uterine cervical mucus, hepatic bile, duodenal contents, pancreatic juices, and in the specific granules of neutrophils (15). In all of the secretions the levels of $L f$ far exceed the levels of transferrin, suggesting that while transferrin is the major iron-binding protein in the serum, Lf plays the major role in external secretions (14).

Serum levels of $\mathrm{Lf}$ range from 0.18 to $1.0 \mu \mathrm{g} / \mathrm{ml}(16-18)$, while plasma levels are between 0.02 and $0.2 \mu \mathrm{g} / \mathrm{ml}(16)$. In contrast to these relatively low blood levels, Lf levels are significantly higher in several external secretions. In tears, Lf levels range between 1 and $3 \mathrm{mg} / \mathrm{ml}(12-14,19-21)$, accounting for $\sim 15-30 \%$ of the TP (13). In human milk Lf is found at $\sim 1$ $\mathrm{mg} / \mathrm{ml}(15)$. In bronchial secretions $\mathrm{Lf}$ accounts for as much as $11.5 \%$ of the TP (22).

It should be recognized that some of these secretions are obtained from tissues that may be infiltrated with inflammatory cells such as activated neutrophils. Since neutrophils contain up to 6-8 $\mu \mathrm{g} \mathrm{Lf} / 10^{6}$ cells (5), at least some of the measured Lf may be derived from neutrophils. However, neutrophils cannot account for the high Lf levels measured in normal tears, human milk, or the nasal secretions stimulated by nasal provocation in this study, since neutrophils are not present in significant concentrations in these secretions $(<1,000$ cells $/ \mathrm{ml}$ in nasal lavage fluid).

Ly is another antimicrobial protein found in nasal secretions as well as in many other external secretions. It is a much smaller molecule than Lf with a molecular weight of $\sim 14,000$. It is a bactericidal protein that enzymatically degrades the bacterial cell walls of susceptible bacteria. It is a ubiquitous protein found in humans as well as many other mammalian species. It has even been found in vegetables such as the turnip (23).

Ly was first reported in nasal secretions by Fleming in 1922 when he discovered that nasal secretions from a patient with catarrh had a remarkable ability to kill common bacterial species like $M$. lysodeikticus, in addition to several other different strains of bacteria (23). Like Lf, Ly has been found in other

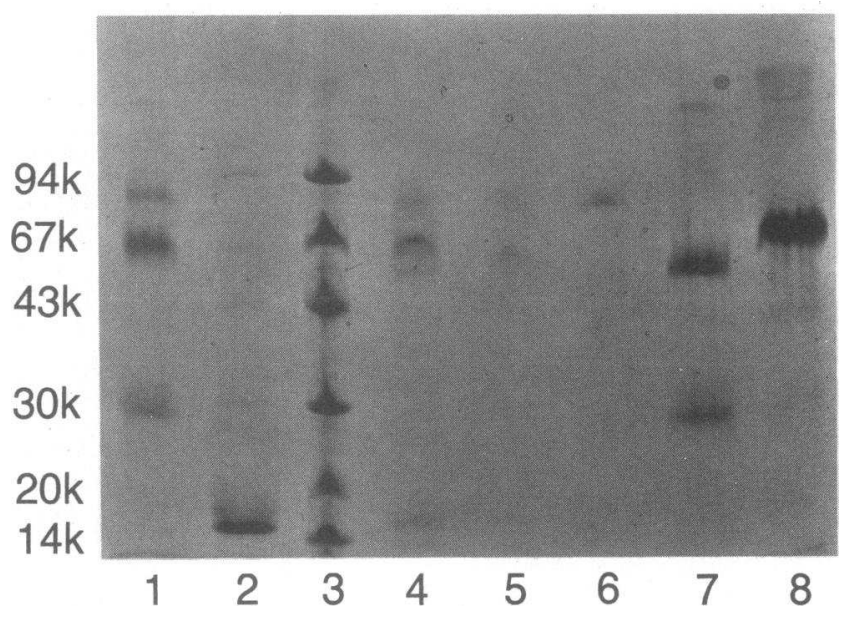

Figure 9. SDS-PAGE analysis of nasal secretions and standard proteins. Samples were electrophoresed on a 10-15\% gradient gel and stained with Coomassie blue stain as described (see text). Baseline nasal secretions (lane 5) produced only a few discernable protein bands, several of which are accentuated in MC-induced secretions (lane 4). Standards of IgA (lane 1), Ly (lane 2), Lf (lane 6), IgG (lane 7), and Alb (lane 8) are shown for comparison. Low molecular weight markers are in lane 3 .

secretions including tears, bronchial mucus, plasma, sebum, and pus (24). It has been histologically identified in the proximal tubules of the kidney, the stomach gastric glands, the small intestinal Brunner's glands, Paneth cells, lacrimal glands, parotid glands and ducts, bronchial glands, submandibular and sublingual salivary glands, and neutrophils and macrophages $(24,25)$.

As with Lf, Ly is a major protein in tears and is found in concentrations between 1 and $3 \mathrm{mg} / \mathrm{ml}(10,11,21)$. In the lung it accounts for nearly $5-6 \%$ of the total protein (22). As with Lf, serum levels of Ly are low, with normal levels reported to be $1.0-1.5 \mu \mathrm{g} / \mathrm{ml}(26)$.

Ly levels in external secretions vary with age and developmental status. In newborn (full-term) babies the Ly levels are approximately at normal adult levels (27). However, in premature babies ( $<32 \mathrm{wk}$ of gestation) or in fetuses dying before $32 \mathrm{wk}$ the Ly content measured from the lung was considerably below normal, suggesting that this protein develops relatively late in utero. With advancing age, however, the levels of both Ly and Lf decrease $(10,21)$.

The current study demonstrates that both Lf and Ly are

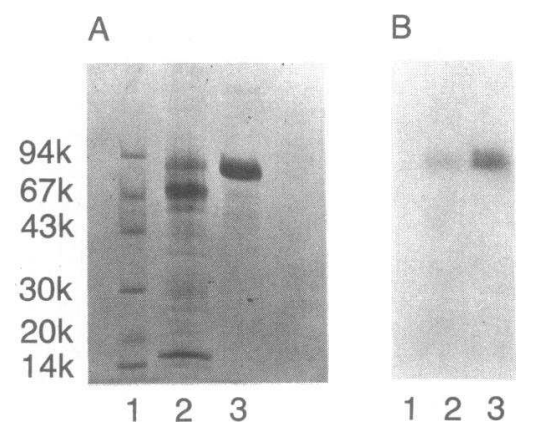

Figure 10. Immunological identification of $\mathrm{Lf}$ in nasal secretions. In $A$, a $10-15 \%$ gradient SDS-PAGE was performed on low molecular weight markers (lane 1), MC-induced nasal secretions (lane 2), and a Lf standard (lane 3). A second identical gel, run in parallel, was immunoblotted with antihuman $\operatorname{Lf}(B)$. The immunoblot identifies the presence of $L f$ in nasal secretions. 

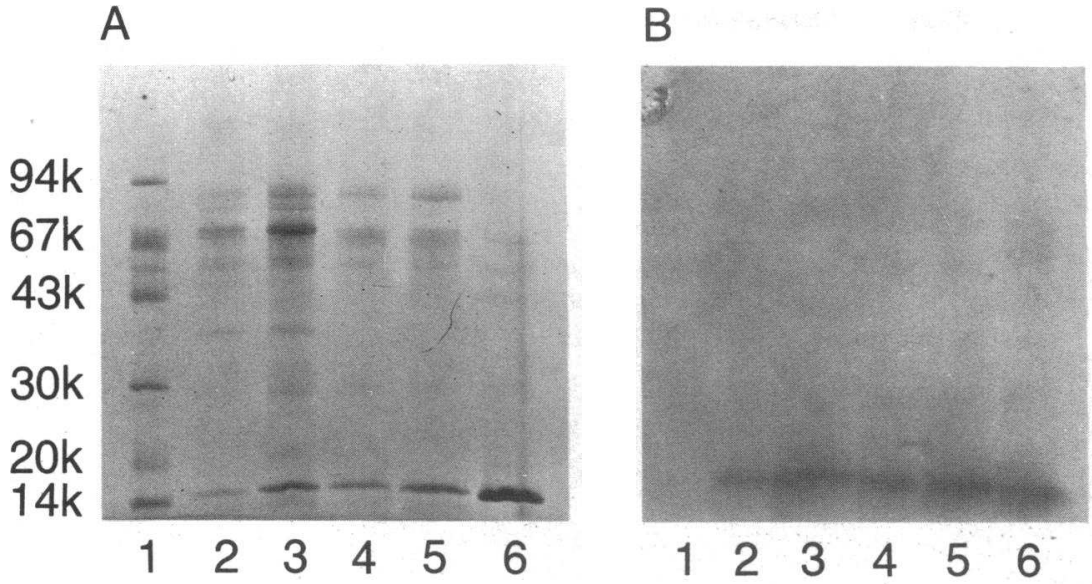

Figure 11. Immunological identification of Ly in nasal secretions. In $A$, a $10-15 \%$ gradient SDSPAGE was performed on low molecular weight markers (lane 1), four samples of MC-induced nasal secretions (lanes 2-5), and a Ly standard (lane 6). In $B$, an immunoblot of a second identical gel run in parallel was stained for anti-human Ly, demonstrating the immunological presence of Ly in all four samples.

important constituents of nasal secretions. Gel electrophoresis studies, in conjunction with Western blot analyses, confirmed that these proteins are two of the major constituents of nasal secretions. After nasal challenge with cholinergic stimulation (with MC or gustatory stimuli), both Lf and Ly were selectively secreted (compared with baseline levels) into nasal secretions as assessed quantitatively by ELISA and functional assays and qualitatively by electrophoretic analysis. Furthermore, since $\mathbf{H}$ stimulation did not augment the proportion of either Lf\% or $\mathrm{Ly} \%$, as it reliably does with serum proteins such as Alb and IgG (2), these data strongly suggest that both Lf and Ly are proteins secreted from the glands in the nose. This suggestion is further supported by histochemical studies that unequivocally demonstrate the presence of both proteins within submucosal glandular serous cells (Fig. 12). Furthermore, when the lacrimal glands were blocked with anticholinergic agents, cholinergic stimulation of the nose again increased Lf and Ly secretion, as well as the Lf\% and Ly\%, confirming that both proteins were secreted specifically from the glands in the nose, not from contamination of nasal secretions by tears.

Both Lf and Ly have been identified within the secretory granules of serous cells in the nose as well as in several other exocrine glands including the salivary glands, lacrimal glands, and submucosal glands in the lung $(24,25,28-33)$. However, the histochemical distribution of these proteins within the glandular structure appears to vary depending on which tissue is being examined. In the nasal mucosa and in bronchial mucosa $\mathrm{Lf}$ and Ly were both found in acinar and ductal serous cells but not in mucous cells (28). Serial sections of the nasal mucosa in this study confirm the simultaneous colocalization

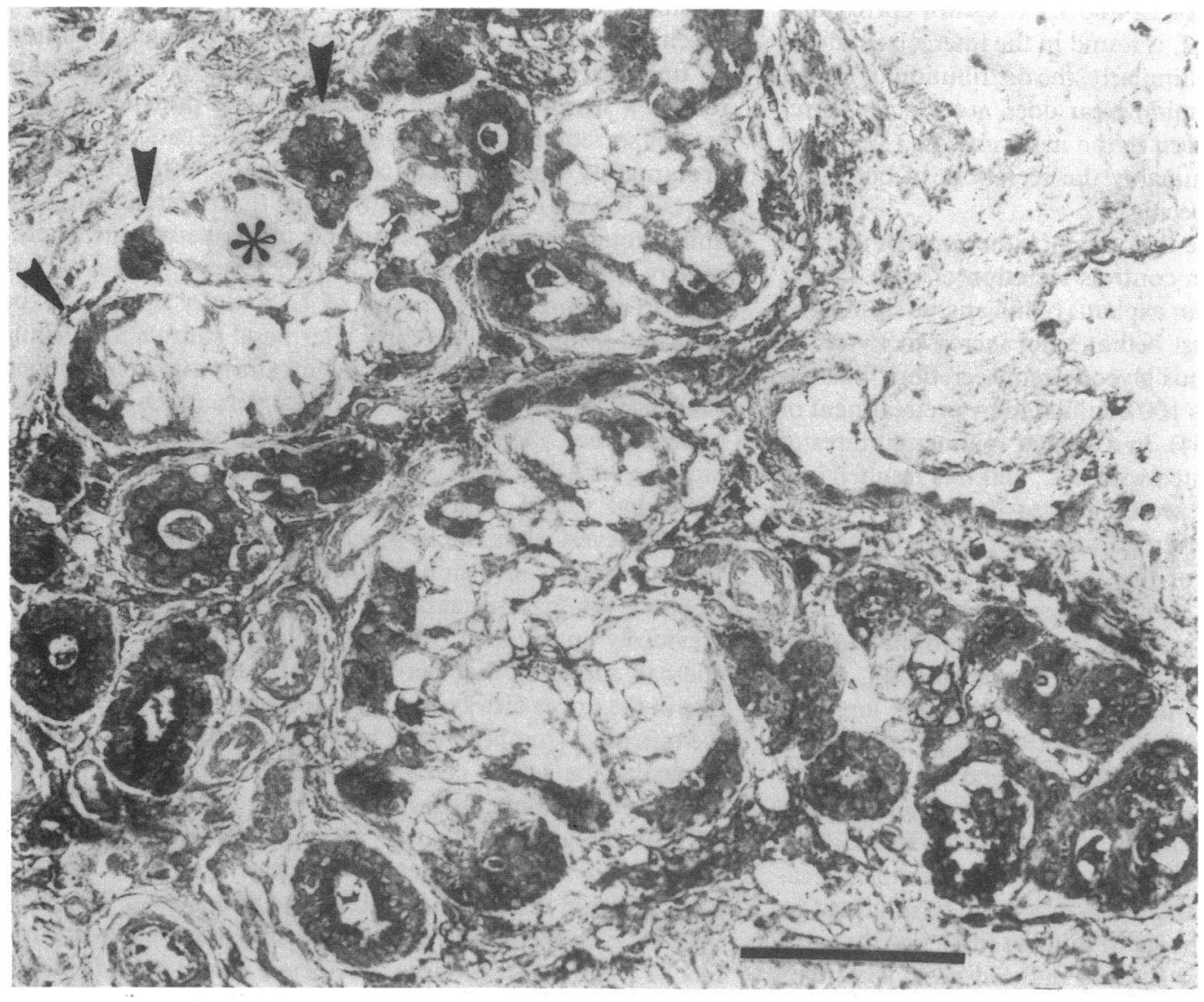

Figure 12. Lf immunoreactivity in submucosal glands. Lf immunoreactivity (dark stain, arrow heads) is seen only in serous cells of submucosal glands. Mucous cells (clear cells, asterisk) do not stain for Lf. Bar, 100 $\mu \mathrm{m}$. 


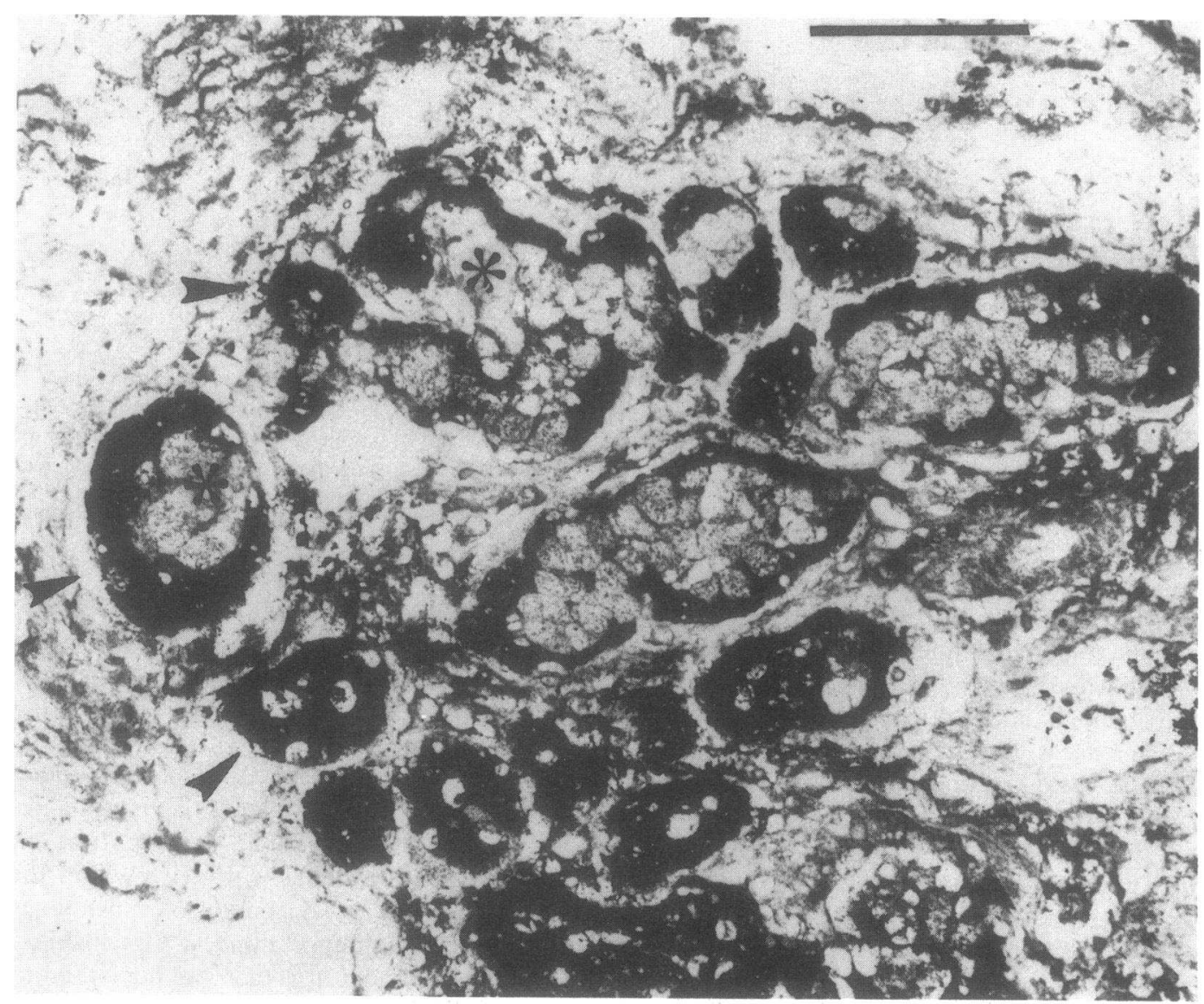

Figure 13. Ly immunoreactivity in submucosal glands. Ly immunoreactivity (dark stains, arrow heads) is seen only in serous cells of submucosal glands. Mucous cells (clear cells, asterisk) do not stain for Ly. Bar, 100 $\mu \mathrm{m}$. of both proteins in the same serous cell. In salivary glands, however, the distribution of Lf and Ly does not correspond exactly. Only Ly, but not Lf, is found in the intercalated ducts of the salivary glands (25). Similarly, the distribution of Lf and Ly in the mucosa of the middle ear does not exactly correspond to the distribution seen in the nasal mucosa (32). Thus the distribution, and presumably the secretion, of both proteins appear to be tissue specific.

There is much evidence that supports the concept that the cholinergic nervous system controls secretion of both $\mathrm{Lf}$ and Ly. In a tissue culture system explants of lung tissue stimulated with the cholinergic agonist bethanechol increased Ly secretion in parallel with mucous glycoprotein secretion. This increased secretion of Ly was $100 \%$ inhibited by pretreatment of the tissue with atropine (34). In a similar manner cultures of ferret trachea were stimulated with MC, and this resulted in a significant increase in Ly secretion into the culture media. Ferret Ly secretion was prevented with atropine pretreatment. Histological examination of this ferret trachea tissue before and after MC stimulation showed a remarkable post-MC reduction in both serous cell granules and in Ly immunoreactive staining (33). In a third study reflex-stimulated tears, which invoke a cholinergic efferent pathway, produced a large increase in Ly secretion as compared with baseline levels (35). All three studies confirm the findings described in the current nasal provocation study, in which cholinergic stimulation selectively increased the secretion of both Lf and Ly. In addition, preliminary data from this lab suggest that the cholinergic-induced increases in both Lf and Ly secretion can be inhibited by atropine pretreatment of the nasal mucosa (data not shown).

The secretion of $\mathrm{Lf}$ and $\mathrm{Ly}$ into induced nasal secretions increased in parallel, with a high degree of significance, after cholinergic stimulation (Table II). It is apparent, however, that much more Ly is secreted into nasal secretions than Lf (almost 10 times as much). This difference in relative concentration reflects a significant difference between the protein constituents in secretions from the nose and tears. Tears contain approximately the same concentrations of both Lf and Ly ( $\sim 1-3 \mathrm{mg} / \mathrm{ml}$ of each protein). Thus this difference in glandular protein constituents represents the tissue-specific heterogeneity referred to previously.

Furthermore, the secretion of Lf and Ly appears to be regulated somewhat differently after nasal stimulation. While both proteins increased in concentration after cholinergic challenge, clearly the secretion of Ly was much more pronounced, the Ly\% nearly tripled, and there was a much smaller increase in $\mathrm{Lf} \%$. Similarly, $\mathrm{H}$ stimulation also produced a somewhat varied response, with the Lf\% decreasing below baseline levels while the Ly\% was essentially unchanged.

One major conclusion that is supported by this and other studies is that nasal secretions serve more functions than were previously appreciated. In addition to providing lubrication, one can speculate that the submucosal gland's predominant role in the upper airways is to provide a first line of defense for the mucosa. It has been demonstrated that the nasal glands (in particular the serous cells) process and secrete sIgA (1), the major Ig of not only the respiratory tract, but the entire mucosal immune tract. If one now adds the observation from this paper that two other protective proteins, $\mathrm{Lf}$ and $\mathrm{Ly}$, are also processed and secreted from glandular serous cells, it appears that the glands secrete both nonspecific and specific antimicrobial factors in response to cholinergic stimulation. It should 
also be noted that other protective proteins such as bronchial protease inhibitor (30) and salivary peroxidase (31) have been identified within submucosal gland serous cells in other mucosal tissues, suggesting the concept that submucosal glands (and particularly the serous cells) throughout the entire mucosal immune system function as a repository of antimicrobial proteins, prepared to provide the mucosa with its first line of defense against a whole host of external pathogens. Based on the pharmacologic responses noted in this and other related papers $(1,2,31,33){ }^{2}$ it may be possible, in the future, to pharmacologically regulate secretions from the submucosal glands to help facilitate the secretion of these antimicrobial factors. Moreover, the appreciation of the sources, regulation, and properties of these factors are certain to lead to an improved understanding of the normal function of the mucosa in host-defense systems.

\section{Acknowledgments}

The authors would like to thank Dr. Steven Banks for providing the statistical analyses used in preparing this manuscript, and Dr. Alan Palestine, Dr. Janet Davis, and Dr. Jeffrey Bloom for providing the patients with ocular disease used in this study.

Dr. Jeney was supported by a fellowship provided by the Silverman Foundation in conjunction with the University of Toronto. Dr. Baraniuk was supported in part by a fellowship provided by Proctor and Gamble. Dr. Meredith was supported by a fellowship provided by the Merck Foundation.

\section{References}

1. Raphael, G. D., H. M. Druce, J. N. Baraniuk, and M. A. Kaliner. 1988. The pathophysiology of rhinitis. I. Assessment of the sources of protein in methacholine-induced nasal secretions. Am. Rev. Respir. Dis. 138:413-420.

2. Raphael, G. D., S. D. Meredith, J. N. Baraniuk, H. M. Druce, S. M. Banks, and M. A. Kaliner. The pathophysiology of rhinitis. II. Assessment of the sources of protein in histamine-induced nasal secretions. Am. Rev. Respir. Dis. 139:791-800.

3. Raphael, G., M. Hauptschein-Raphael, and M. Kaliner. 1989. Gustatory rhinitis: a syndrome of food-induced rhinorrhea. J. Allergy Clin. Immunol. 83:110-115.

4. Lowry, O. H., N. J. Rosebrough, A. L. Farr, and R. J. Randall. 1951. Protein measurement with the Folin phenol reagent. J. Biol. Chem. 193:265-275.

5. Metcalf, J. A., J. I. Gallin, W. M. Nauseef, and R. K. Root. 1986. Lysozyme. In Laboratory Manual of Neutrophil Function. Raven Press, New York. 149-150.

6. White, M. V., and M. A. Kaliner. 1987. Neutrophils and mast cells. I. Human neutrophil-derived histamine-releasing activity. J. Immunol. 139:1624-1630.

7. Pharmacia LKB Technique File \#110.

8. Pharmacia LKB Technique File \#200.

9. Pharmacia LKB Technique File \#220.

10. Mackie, I. A., and D. V. Seal. 1984. Diagnostic implications of tear protein profiles. Br. J. Ophthalmol. 68:321-324.

11. Velos, P., P. M. H. Cherry, and D. Miller. 1985. An improved method for measuring human tear lysozyme concentrations. Acta Ophthalmol. 103:31-33.

12. Ballow, M., P. C. Donshik, P. Rapacz, and L. Samartino. 1987. Tear lactoferrin levels in patients with external inflammatory ocular disease. Invest. Ophthalmol. \& Visual Sci. 28:543-545.

13. Kijlstra, A., S. H. M. Jeurissen, and K. M. Koning. 1983. Lactoferrin levels in normal human tears. Br. J. Ophthalmol. 67:199202.

14. Masson, P. L., J. F. Heremans, and C. H. Dive. 1966. An iron-binding protein common to many external secretions. Clin. Chim. Acta. 14:735-739.
15. Hegnhoj, J., and O. B. Schaffalitzky de Muckadell. 1985. An enzyme-linked immunosorbent assay for measurements of lactoferrin in duodenal aspirates and other biological fluids. Scand. J. Clin. Invest. 45:489-495.

16. Otnaess, A. B. K., A. Meberg, and H. A. Sande. 1983. Plasma lactoferrin measured by an enzyme-linked immunosorbent assay (ELISA). Scand. J. Haematol. 31:235-240.

17. Chung, S., C. Hayward, D. J. H. Brock, and V. van Hayningen. 1985. A monoclonal antibody-based immunoassay for human lactoferrin. J. Immunol. Methods. 84:135-141.

18. Hetherington, S. V., J. K. Spitznagel, and P. G. Quie. 1983. An enzyme-linked immunoassay (ELISA) for measurement of lactoferrin. J. Immunol. Methods. 65:183-190.

19. Modig, J., T. Samuelson, and R. Hallgren. 1986. The predictive and discriminative value of biologically active products of eosinophils, neutrophils, and complement in bronchoalveolar lavage and blood in patients with adult respiratory distress syndrome. Resuscitation. 14:121-134.

20. Fullard, R. J. 1988. Reliability of human tear protein identifcation assay is improved by HPLC fractionation of tear samples. Invest. Ophthalmol. \& Visual Sci. 29(Suppl):47.

21. Jensen, O. L., and B. Sand. 1987. Lactoferrin and serum albumin in the conjunctival fluid of eyes operated for senile cataracts. Acta Ophthalmol. 65:393-396.

22. Harbitz, O., A. O. Jenssen, and O. Smidsrod. 1984. Lysozyme and lactoferrin in sputum from patients with chronic obstructive lung disease. Eur. J. Respir. Dis. 65:512-520.

23. Fleming, A. 1922. On a remarkable bacteriolytic element found in tissues and secretions. Proc. R. Soc. Lond. B Biol. Sci. 93:306-317.

24. Klockars, M., and S. Reitamo. 1975. Tissue distribution of lysozyme in man. J. Histochem. Cytochem. 23:932-940.

25. Korsrud, F. R., and P. Brandtzaeg. 1982. Characterization of epithelial elements in human major salivary glands by functional markers: localization of amylase, lactoferrin, lysozyme, secretory component, and secretory immunoglobulin by paired immunofluorescence staining. J. Histochem. Cytochem. 30:657-666.

26. Francina, A., H. Cloppet, R. Guinet, M. Rossi, D. Guyotat, O. Gentilhomme, and M. Richard. 1986. A rapid and sensitive non-competitive avidin-biotin immuno-enzymatic assay for lysozyme. J. Immunol. Methods. 87:267-272.

27. Lehtonen, O. P. J., J. Tenovuo, A. S. Aaltonen, and P. Vilja. 1987. Immunoglobulins and innate factors of immunity in saliva of children prone to respiratory infections. Acta Pathol. Microbiol. Scand. Sect. C Immunol. 95:35-40.

28. Bowes, D., A. E. Clark, and B. Corrin. 1981. Ultrastructural localisation of lactoferrin and glycoprotein in human bronchial glands. Thorax. 36:108-115.

29. Janssen, P. T., and O. P. van Bjisterveld. 1983. Origin and biosynthesis of human tear fluid proteins. Invest. Ophthalmol. \& Visual Sci. 24:623-630.

30. Jeffrey, P. K. 1987. The origins of secretions in the lower respiratory tract. Eur. J. Respir. Dis. 71(Suppl 153):34-42.

31. Rudney, J. D., and Q. T. Smith. 1985. Relationship between levels of lysozyme, lactoferrin, salivary peroxidase, and secretory immunoglobulin A in stimulated parotid saliva. Infect. Immun. 49:469475.

32. Saito, H., T. Kasajima, A. Masuda, Y. Imai, and M. Ishikawa. 1988. Lysozyme localization in human gastric and duodenal epithelium: an immunocytochemical study. Cell Tissue Res. 251:307-313.

33. Tom-Moy, M., C. B. Basbaum, and J. A. Nadel. 1983. Localization and release of lysozyme from ferret trachea: Effects of adrenergic and cholinergic drugs. Cell Tissue Res. 228:549-562.

34. Boat, T. F., J. I. Kleinerman, A. A. Fanaroff, and R. C. Stern. 1977. Human tracheobronchial secretions: development of mucous glycoprotein and lysozyme-secreting systems. Pediatr. Res. 11:977980.

35. Stuchell, R. N., R. L. Farris, and I. D. Mandel. 1981. Basal and reflex human tear analysis. II. Chemical analysis: lactoferrin and lysozyme. Ophthalmology. 88:858-861. 